\title{
Effect of deep cryogenic treatment and tempering on microstructure and mechanical behaviors of a wear-resistant austempered alloyed bainitic ductile iron
}

\author{
Liqing Chen ${ }^{1, a}$, Junjun Cui ${ }^{1}$, and Weiping Tong ${ }^{2}$ \\ ${ }^{1}$ State Key Laboratory of Rolling and Automation, Northeastern University, 3-11 Wenhua Road, \\ Shenyang 110819, PR China \\ ${ }^{2}$ Key Laboratory for Electromagnetic Processing of Materials (Ministry of Education), Northeastern \\ University, 3-11 Wenhua Road, Shenyang 110819, PR China
}

\begin{abstract}
In this paper, the effect of deep cryogenic treatment in combination with conventional heat treatment process was investigated on microstructure and mechanical behaviors of alloyed bainitic ductile iron. Three processing schedules were employed to treat this alloyed ductile iron including direct tempering treatment, tempering.+deep cryogenic treatment and deep cryogenic treatment.+tempering treatments. The microstructure and mechanical behavior, especially the wear resistance, have been evaluated after treated by these three schedules. The results show that martensite microstructure can be obviously refined and the precipitation of dispersed carbides is promoted by deep cryogenic treatment at.$-196^{\circ} \mathrm{C}$ for $3 \mathrm{~h}$ after tempered at $450^{\circ} \mathrm{C}$ for $2 \mathrm{~h}$. In this case, the alloyed bainitic ductile iron possesses rather high hardness and wear-resistance than those processed by other two schedules. The main wear mechanism of the austempered alloyed ductile iron with deep cryogenic treatment and tempering is micro-cutting wear in association with plastic deformation wear.
\end{abstract}

\section{Introduction}

Bainitic ductile irons have long been considered candidate materials for wear-resistant components in mining and minerals industry due to their excellent impact toughness, strength and abrasion resistance provided by the bainite, eutectic carbides and graphite in the microstructure [1,2]. There are two routes to obtain bainite microstructure. The first is to optimize alloying elements like $\mathrm{Mo}, \mathrm{Ni}, \mathrm{Mn}$ and $\mathrm{Cu}$ etc. by adding $0.2-5.0 \mathrm{wt} . \%$ in as-cast state which can amplify the austenite transformation field and make the bainitic transformation field move far and separate with pearlitic transformation field [3], while the second is realized by austempering heat treatment which need to control the austempering parameters including austempering time and temperature $[4,5]$. Austempering heat treatment contains two stages. In stage I, the austenite matrix with high carbon content isothermally transforms into ausferrite, while in stage II the stabilized austenite decomposes into ferrite and carbides [6]. Higher strength and hardness can be obtained by adding $\mathrm{Cr}$ and $\mathrm{V}$ as alloying elements.

\footnotetext{
${ }^{\text {a }}$ Corresponding author: Iqchen@mail.neu.edu.cn
}

This is an Open Access article distributed under the terms of the Creative Commons Attribution License 4.0, which permits unrestricted use, distribution, and reproduction in any medium, provided the original work is properly cited. 


\section{MATEC Web of Conferences}

In order to further improve the hardness and wear resistance of the cast iron, the deep cryogenic treatment, as an effective way, can be used to modify the microstructure. Most researchers believe that cryogenic treatment will fully promote the transformation of retained austenite into martensite and lead to improvement of wear resistance [7]. A little improvement in hardness of die steel, tool steel and 4140 steel has been reported by D. Das et al. [8], A. Molinari et al. [9] and A. Oppenkowsk et al. [10], when the cryogenic treatment process was performed after conventional heat treatment. However, the mechanical behaviors could be obviously improved if the cryogenic treatment process was performed prior to the tempering treatment.

As far as deep cryogenic treatment in combination with conventional heat treatment is concerned, till now there has been little information available for alloyed bainitic ductile iron. By using optical microscopy (OM), scanning electron microscopy (SEM) and X-ray diffraction (XRD), the effect of different cryogenic treatment sequence together with tempering treatment on the matrix structure, hardening behavior and wear resistance of austempered alloyed bainitic ductile iron was investigated in this paper. The results are presented and a discussion was finally made with an attempt to correlate the mechanical behavior with microstructures.

\section{Experimental}

The material used in this experiment is alloyed bainitic ductile iron. The chemical composition containing (in wt pet) $3.55 \mathrm{C}, 1.97 \mathrm{Si}, 0.36 \mathrm{Mn}, 3.79 \mathrm{Ni}, 0.708 \mathrm{Cu}, 0.92 \mathrm{Mo}, 0.637 \mathrm{Cr}, 0.3 \mathrm{~V}$ and balanced Fe, was thermodynamically designed by Thermo-Calc software. The pig iron was melted in a medium frequency induction furnace ( 5 ton capacity). When the temperature of molten iron reached to $1460{ }^{\circ} \mathrm{C}$, the prepared nickel plate, molybdenum iron, ferrochrome, ferromanganese and ferrosilicon were added to the furnace. The molten iron with certain alloy composition was poured into a ladle where the $\mathrm{Cu}-\mathrm{Mg}$ alloy and alloy $6 \#$ (containing 44\% $\mathrm{Si}, 4-6 \% \mathrm{RE}, 7-9 \% \mathrm{Mg},<4 \% \mathrm{Mn},<3.0 \% \mathrm{Ca}$, $1 \% \mathrm{Ti}$ and balanced $\mathrm{Fe}$ ) had been added as nodulizer and a $\mathrm{Si}-\mathrm{Ba}$ alloy added as inoculant. After the ladle cooled to $1360^{\circ} \mathrm{C}$, the molten iron was then poured into the mold in a centrifugal casting machine rotating at a speed of $750 \mathrm{rpm}$. The dimension of cast ingot is $\varphi 590 \mathrm{~mm} \times 1700 \mathrm{~mm}$.

The specimens for subsequent heat treatments were cut from the roller surface. At first, they were austenitized at $850^{\circ} \mathrm{C}$ for $1 \mathrm{~h}$ and then rapidly austempered at $300^{\circ} \mathrm{C}$ in a salt bath for $2 \mathrm{~h}$. Three processing schedules were employed to treat this austempered alloyed ductile iron including direct tempering treatment (AT, tempered at $450{ }^{\circ} \mathrm{C}$ for $2 \mathrm{~h}$ ), tempering + deep cryogenic treatment (ATD, tempered at $450{ }^{\circ} \mathrm{C}$ for $2 \mathrm{~h}$ followed by quenching in liquid nitrogen bath at $-196^{\circ} \mathrm{C}$ for $3 \mathrm{~h}$ ) and deep cryogenic + tempering treatment (ADT, quenched in liquid nitrogen bath at $-196^{\circ} \mathrm{C}$ for $3 \mathrm{~h}$, and then followed by tempering at $450{ }^{\circ} \mathrm{C}$ for $2 \mathrm{~h}$ ).

After mechanically polished and etched in 4 vol.\% nital solution at room temperature, the microstructures of the austempered sample with different treatment processes were observed in an optical microscope (OM, LEICA Q550IW) and a scanning electron microscope (SEM, FEI Quanta 600). X-ray diffraction (XRD, Rigaku D/Max-2500PC) patterns of these samples were analyzed in order to further confirm the constituent phases and their changes. The amount of retained austenite was calculated according to ASTM-E975.

The hardness was measured on Rockwell $\mathrm{C}$ scale. For each sample an average of ten readings was noted at different locations. The abrasive wear resistance of the austempered ductile iron sample with deep cryogenic and tempering treatment was evaluated in a conventional method with a dry sand/rubber wheel apparatus which was built based on ASTM-G65 standard. The relative wear resistance was taken as the reciprocal of the weight loss $W_{L}(\mathrm{~g})$, i.e.

$$
\varepsilon=1 / W_{L}
$$

The worn surface morphologies of the samples were characterized by a scanning electron microscope. 


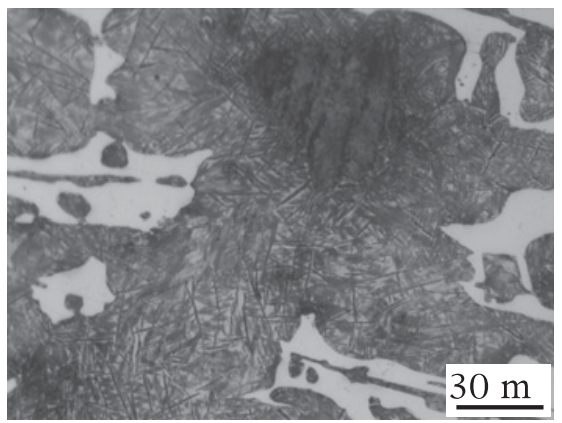

Figure 1. The optical microstructure of the alloyed ductile iron in isothermal quenching state.

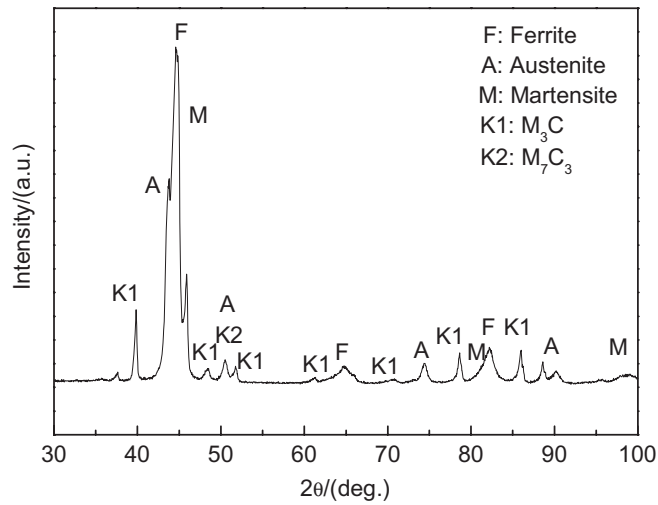

Figure 2. The XRD pattern of the austempered alloyed bainitic ductile iron.

\section{Results and discussion}

\subsection{Microstructure}

The optical microstructure of the alloyed bainitic ductile iron under the austempered condition is shown in Fig. 1 Typically, the austempered alloyed bainitic ductile consists of discontinuous eutectic carbide, acicular bainite, residual austenite, martensite with graphite dispersed in the matrix [11]. Figure 2 is the corresponding X-ray diffraction pattern of the austempered alloyed bainitic ductile iron, which shows that the microstructural constituents are austenite, $\mathrm{M}_{3} \mathrm{C}$ and $\mathrm{M}_{7} \mathrm{C}_{3}$ carbides, martensite and ferrite. The content of austenite was calculated to be $28.6 \%$ (in volume percentage). Using quantitative metallographic analysis, the content of the eutectic carbide was evaluated to be $28.8 \%$.

As shown in Fig. 3(a), after direct tempering at $450{ }^{\circ} \mathrm{C}$, the needle-like bainite began to grow and coarsen. As the bainitic needle became coarsen, the carbon content in austenite increased. However, it is insufficient to build up a stabilized level for all austenite and some of them would transform into martensite when it was air cooled to room temperature. The resulting microstructure, composed of ferrite, $\mathrm{M}_{3} \mathrm{C}$ carbide phases (precipitates from the process that the retained austenite transformed into martensite during tempering treatment), martensite and austenite, can be observed according to the XRD pattern in Fig. 4. From the metallographic photos in Fig. 3(b), we can see that the residual austenite further transformed into martensite when deep cryogenic treatment was performed after the tempering processing. Thus, the martensite will owns the higher hardness compared to the tempered sample due to the carbon content in the martensite is higher. The morphology of martensite in the austempered ductile 

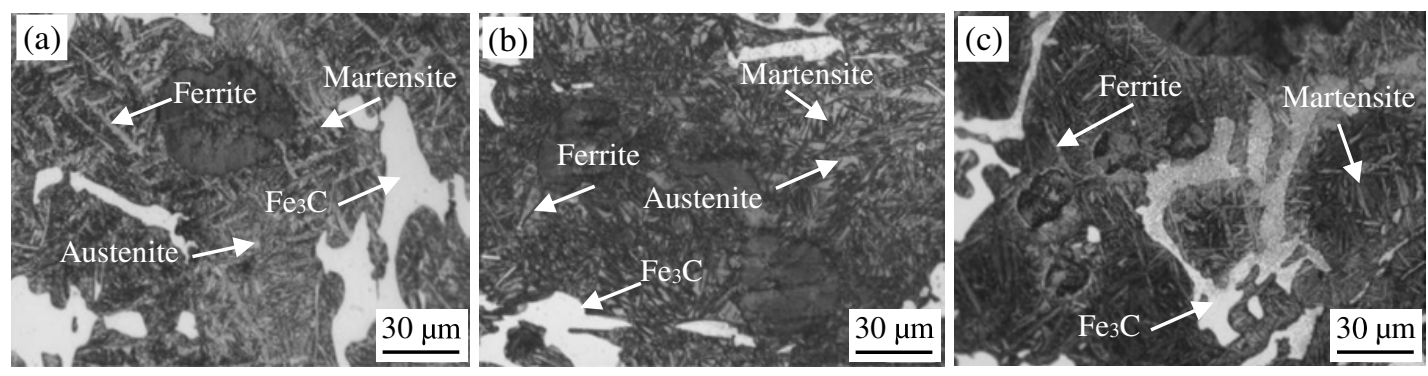

Figure 3. The optical microstructure of the austempered alloyed ductile iron with heat treatments denoted by AT (a), ATD (b) and ADT (c).

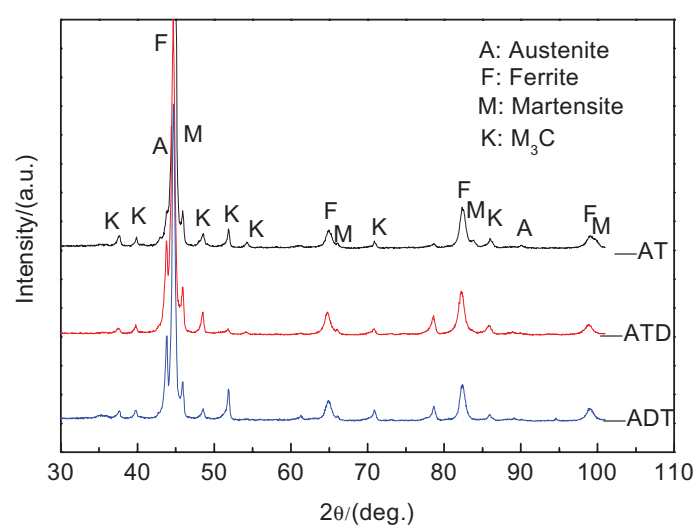

Figure 4. The XRD patterns of the austempered alloyed ductile iron with AT, ATD and ADT heat treatments.

iron with ADT treatment has an obvious distinction from other two heat treated samples shown in Fig. 3(c). Comparing the intensity of X-ray diffraction peak of the samples with the three heat treatment processes, it can be found that amount of $\mathrm{M}_{3} \mathrm{C}$ carbide increased. The austempred bainitic ductile iron was directly immersed at $-196^{\circ} \mathrm{C}$, the unstable austenite further transformed to fresh martensite. And the fresh martensite looks like straw which owns high hardness [12]. The carbon atoms could not move at such a low temperature which led to more carbon atoms trapped in the martensite, so the arrangement of carbon atoms was very disordered. This phenomenon was conducive to release the microscopic stress and promote carbide precipitation after subsequent tempering. Moreover, the segregated carbon atoms produce a strong interaction with strain field of dislocations caused by martensitic transformation and form clusters which act as nuclei for carbide formation during subsequent tempering.

Figure 5 is the SEM photos of martensite morphology at different treatment states. From Fig. 5(a) and (b), it can be found that the martensite morphology of the sample with deep cryogenic after tempering treatment is similar to that after direct tempering. The martensite is flake-like, and the adjacent martensite needle is not parallel. However, the martensite morphology of the sample after deep cryogenic treatment before tempering is obviously different from the flake-like martensite. The morphology of martensite is fine and long, and the orientation of martensite is not obvious, which can be inferred that the growth mode of martensite differs from that after conventional heat treatment. Moreover, the morphology of martensite would not be changed with subsequent tempering treatment. 

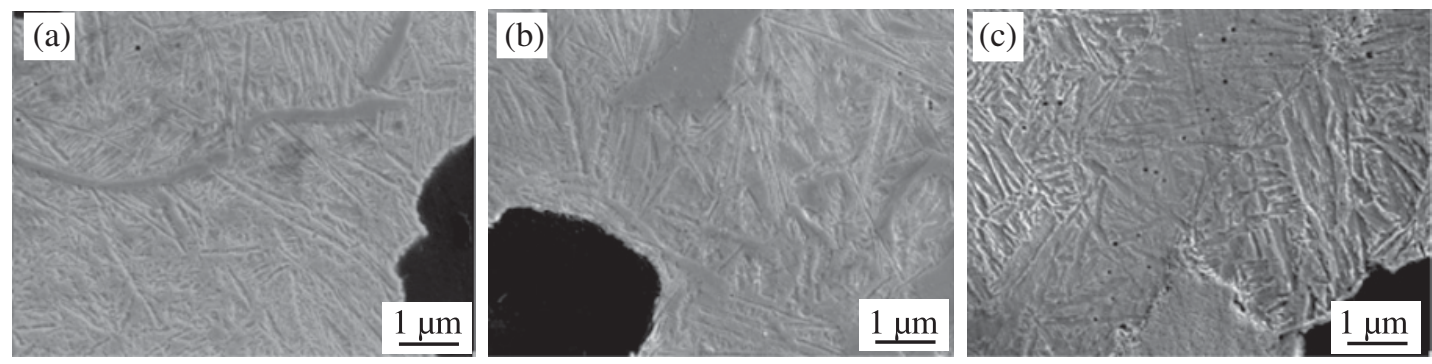

Figure 5. SEM photos of martensite in the austempered alloyed ductile iron with AT (a), ATD (b) and ADT (c) heat treatments.

Table 1. Hardness of the austempered alloyed ductile iron under different heat treatments.

\begin{tabular}{|l|l|l|l|}
\hline Heat treatment process & AT & ATD & ADT \\
\hline Hardness (HRC) & 57.7 & 61.3 & 59.0 \\
\hline
\end{tabular}

\subsection{Effect of deep cryogenic treatment on hardness}

Table 1 lists hardness value of the alloyed ductile iron subjected to austempered treatment followed by three different treatment schedules, i.e. AT, ATD and ADT.

A comparison of the hardness values for AT and ATD samples indicates that there is an increase of hardness for the sample after cryogenic treatment. The reason for hardness increase can be attributed to two aspects. One is that austenite with higher carbon content in the tempered sample transform into plate-like martensite. The other is caused by plastic deformation during martensitic transformation at lower temperature, which can lead to dissolving of some coarse carbide particles. This can be inferred from the disappearance of some $\mathrm{M}_{3} \mathrm{C}$ peaks in XRD pattern (Fig. 4). So, the martensite became more supersaturated at cryo-temperature, which increased the lattice distortion and thermodynamic instability of the martensite. This brings carbon and alloying atoms to segregate, and thus the finer carbide precipitated.

The hardness value of the sample after ATD treatment is higher than that after ADT treatment, which is mainly due to Ostwald ripening of the precipitated carbides in the sample with ADT process and thus affects their dispersion hardening. And Ostwald ripening is an observed phenomenon in solid solutions which describes small crystals or particles dissolve, and redeposit onto larger crystals or particles [2]. The microstructure was substantially disordered which caused by splat-cooling during deep cryogenic treatment, and this was conducive to release the microscopic stress. Since the cryotreated sample was further tempered at $450{ }^{\circ} \mathrm{C}$, it caused the appearance of over tempering. This can be confirmed by XRD pattern of the sample after ADT treatment in Fig. 4, where there exists more amount of $\mathrm{M}_{3} \mathrm{C}$ carbide precipitated in microstructure of the ADT sample.

\subsection{Abrasive wear resistance}

Table 2 shows that in the three-body abrasion test the wear resistance of the alloyed bainitic ductile iron was increased in different treatment processes as the hardness was increased. The abrasion test belongs to bulk abrasive wear, so abrasive sliding and rolling existed at the surface of sample during the test. The abrasive sliding creates cutting wear and numerous grooves can be observed in Fig. 6, which presents the morphologies of the worn surfaces of samples with AT, ATD and ADT treatments. The tempered sample has lowest hardness value, so the grooves are increased. Abrasive rolling would create spalled pits at sample surface and lead to repeated plastic deformation of the material. 


\section{MATEC Web of Conferences}

Table 2. Wear resistance of the austempered alloyed ductile iron under different heat treatments.

\begin{tabular}{|l|l|l|l|}
\hline Heat treatment process & AT & ATD & ADT \\
\hline Wear resistance $\left(\mathrm{g}^{-1}\right)$ & 1.428 & 1.853 & 1.534 \\
\hline
\end{tabular}
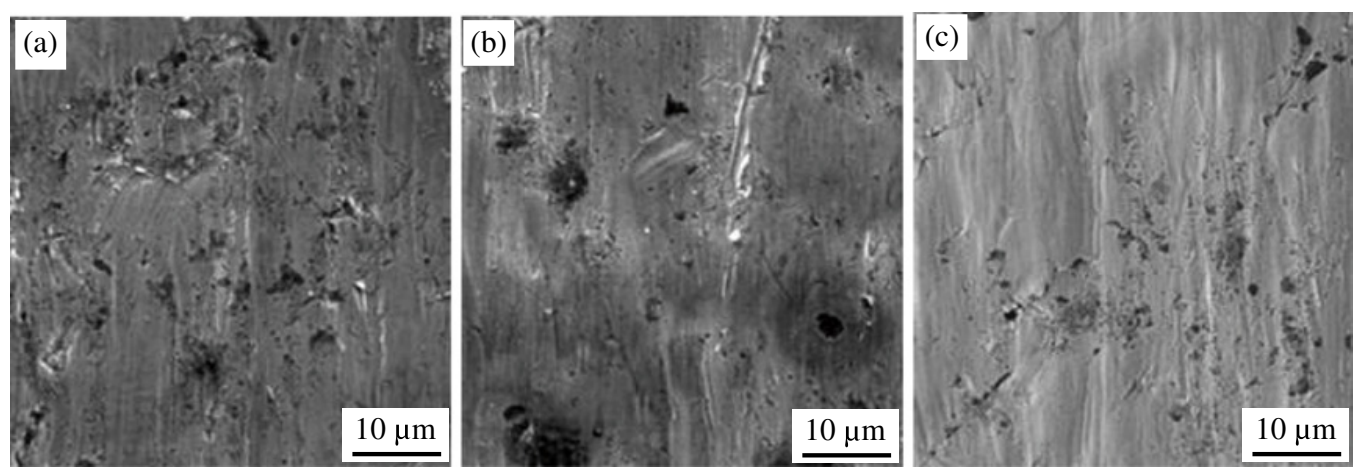

Figure 6. SEM micrographs of worn surfaces in the austempered alloyed ductile iron with AT (a), ATD (b) and ADT (c) heat treatments.

The fatigue crack initiation and propagation caused by the repeated plastic deformation would lead to fatigue spalling. Numerous rolling-pressing pits can be seen in Fig. 6. Owing to the abrasive cutting, the sample surface would be cut off by abrasive prior to fatigue spalling. So, micro-cutting is predominant in three-body hard abrasive wear test. The results obtained in this study indicate that in the abrasive wear test, the ATD sample (austempered alloyed ductile iron with deep cryogenic treatment after tempered at $450{ }^{\circ} \mathrm{C}$ for $2 \mathrm{~h}$ ) has the best abrasive wear resistance, and then is the sample after deep cryogenic treatment plus tempering, and final is the tempered sample.

\section{Conclusions}

(1) The microstructure of the austempered alloyed bainitic ductile iron after tempering contains bainite, $\mathrm{M}_{3} \mathrm{C}$ carbide, martensite and a little austenite, which is similar to that treated by deep cryogenic process after tempering. The martensite morphology was obviously affected in the sample treated by deep cryogenic process before tempering, and there is more amount of $\mathrm{M}_{3} \mathrm{C}$ carbide precipitated.

(2) The austempered alloyed bainitic ductile iron after tempering plus deep cryogenic treatment has the highest hardness and wear resistance, which can be attributed to the formation of more platelike martensite and the finer carbide precipitated. There is a little decrease in hardness of the sample after deep cryogenic treatment plus tempering compared to the sample after tempering plus deep cryogenic treatment, which is due to the occurrence of Ostwald ripening of precipitated carbides.

(3) The wear mechanism of the austempered alloyed ductile iron with deep cryogenic treatment and tempering is mainly micro-cutting wear in association with some plastic deformation wear, and thus the wear resistance still depends on its hardness.

This work was financially supported by the National High Technology Research and Development Program of China (No. 2012AA03A508). 


\section{References}

[1] K.M. Kumar, P. Hariharan, Procedia Eng. 64, 1495 (2013)

[2] H.H. Liu, J. Wang, H.S. Yang, B.L. Shen, Mater. Sci. Eng. A 478, 324 (2008)

[3] J.J. Cui, H.Y. Zhang, L.Q. Chen, H.Z. Li, W.P. Tong, Acta Metall. Sinica (English Letters) 27, $476(2014)$

[4] Y.J. Kim, H. Shin, H. Park, J.D. Lim, Mater. Lett. 62, 357 (2008)

[5] S.C. Murcia, M.A.Paniagua, E.A. Ossa, Mater. Sci. Eng. A 566, 8 (2013)

[6] S. Zahiri, E. Pereloma, C. Davies, Mater. Sci. Technol. 17, 1563 (2001)

[7] C.P. Tabrett, I.R. Sare, J. Mater. Sci. 35, 2069 (2000)

[8] D. Das, K.K. Ray, A.K. Dutta, Wear 267, 1361 (2009)

[9] A. Molinati, M. Pellizzari, S. Gialanella, et al, J. Mater. Process. Technol. 118, 118 (2001)

[10] A. Oppenkowsk, S. Weber, W. Theisen, J. Mater. Process. Technol. 210, 1949 (2010)

[11] O. Erić, D. Rajnović, S. Zec, L. Sidjanin, M.T. Jovanović, Mater. Character 212, 57 (2006)

[12] J. Wang, J. Xiong, H.Y. Fan, H.S. Yang, H.H. Liu, B.L. Shen, J. Mater. Process. Technol. 209, 3236 (2009) 